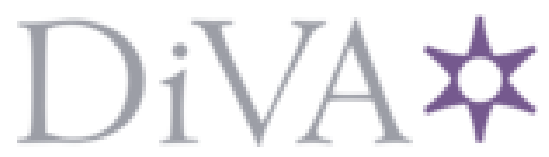

http://www.diva-portal.org

\title{
Postprint
}

This is the accepted version of a paper published in Australasian Journal of Philosophy. This paper has been peer-reviewed but does not include the final publisher proof-corrections or journal pagination.

Citation for the original published paper (version of record):

Åkerman, J. [Year unknown!]

Infelicitous cancellation: The explicit cancellability test for conversational implicature revisited.

Australasian Journal of Philosophy

http://dx.doi.org/10.1080/00048402.2014.988738

Access to the published version may require subscription.

N.B. When citing this work, cite the original published paper.

Permanent link to this version:

http://urn.kb.se/resolve?urn=urn:nbn:se:su:diva- 118632 


\section{INFELICITOUS CANCELLATION: THE EXPLICIT CANCELLABILITY TEST FOR CONVERSATIONAL IMPLICATURE REVISITED}

Jonas Åkerman

This paper questions the adequacy of the explicit cancellability test for conversational implicature as it is commonly understood. The standard way of understanding this test relies on two assumptions: First, that that one can test whether a certain content is (merely) conversationally implicated by checking whether that content is cancellable, and second, that a cancellation is successful only if it results in a felicitous utterance. While I accept the first of these assumptions, I reject the second one. I argue that a cancellation can succeed even if it results in an infelicitous utterance, and that unless we take this possibility into account, we run the risk of misdiagnosing philosophically significant cases.

Keywords: Implicature, Cancellability, Pragmatics, Felicity, Grice

\section{Introduction}

A crucial feature of conversational implicatures as commonly understood is that they are much more loosely connected to the literal content of the utterances that generate them than what these utterances e.g. say or entail. ${ }^{1}$ It is this intuitive feature that is supposed to make

\footnotetext{
${ }^{1}$ Cf. Blome-Tillman [2013: 171].
} 
them cancellable — or, as one may put it, retractable without contradiction ${ }^{2}$ — in contrast to e.g. what is said or entailed. Thus, it is widely thought that a good criterion for determining whether a certain content is (merely) conversationally implicated is to check whether that content is cancellable. ${ }^{3}$ It is also commonly assumed that one can test for successful cancellation by adding a cancellation clause and see if the result is felicitous. ${ }^{4}$ If it is, the cancellation has succeeded; if it is not, it has failed. My aim in this paper is to show that this latter assumption, natural as it may seem, is nevertheless mistaken. Moreover, I argue that its widespread acceptance is problematic, as it may lead to misdiagnosis of philosophically significant cases. This is all the more interesting when we consider the fact that cancellation tests are regularly employed in many different areas of philosophy. ${ }^{5}$

\section{Conversational Implicature and Explicit Cancellability}

First of all, we need some background. Let us start with Grice's own characterization of cancellability:

[A] putative conversational implicature that $p$ is explicitly cancelable if, to the form of words the utterance of which putatively implicates that $p$, it is admissible to add but not $p$, or I do not mean to imply that $p$, and it is contextually cancelable if one can find situations in which the utterance of the form of words would simply not carry the implicature. Now I think that all conversational implicatures are cancelable [. . .]. [Grice 1989: 44]

\footnotetext{
${ }^{2}$ Cf. Bontly [2012: 294].

${ }^{3}$ More generally, anyone — Gricean or not—who acknowledges a category of pragmatically conveyed contents with this intuitive feature can consider the cancellability criterion as a useful device for checking whether a given case belongs to this category.

${ }_{5}^{4}$ For a very recent example, see Dimmock and Huvenes [2014: 3248].

${ }^{5}$ See Blome-Tillmann [2008: 156], who points to the following examples in the literature: Williamson [2000: 248], Finlay [2005: 10-17], and Burton-Roberts [1984: 184-88].
} 
In what follows, the focus will be exclusively on explicit cancellability. Given that we take this form of cancellability as a necessary condition on conversational implicature, ${ }^{6}$ we can extract a simple explicit cancellability test for determining whether one is dealing with a conversational implicature:

$$
\begin{aligned}
& \text { If an utterance } U \text { merely conversationally implicates } p \text {, then it is } \\
& \text { admissible to add a cancellation clause (like 'but not } p \text { ' or 'I do not } \\
& \text { mean to imply that } p \text { ') to } U \text {. }
\end{aligned}
$$

The idea behind the explicit cancellability test is that as long as a certain content $C$ is merely conversationally implicated by an utterance $U$, and thus neither conventionally implicated, semantically entailed, semantically presupposed, nor part of what is said by $U$, it should be admissible to add a clause that denies $C$ (or at least suspends the speaker's commitment to $C$ ), in the sense that such an addition will not render the utterance as a whole infelicitous. So, the thought goes, when the addition of a cancellation clause is not admissible in this sense, we can be sure that we are not dealing with a conversational implicature.

Although tests like EC are frequently employed in many different areas of philosophy, their adequacy has occasionally been challenged. Among the more recent critics is Matthew Weiner [2006], who provides a number of examples of conversational implicatures that do not seem to be explicitly cancellable in the sense employed in EC, and thus fails this test. In response, Michael Blome-Tillmann [2008] has argued that a slight modification EC is

\footnotetext{
${ }^{6}$ For present purposes, I shall accept Blome-Tillmann's [2008: 157] suggestion that explicit cancellability (or rather a weakened version of it) is to be understood as a necessary condition on conversational implicature. However, I am not sure whether this is something we can attribute to Grice. The cited passage, taken from 'Further Notes on Logic and Conversation', and another passage in 'Logic and Conversation' [Grice, 1989: 39], both seem to suggest that he thought that the necessary condition should be disjunctive, i.e. that a conversational implicature should be either explicitly or contextually cancellable.
} 
sufficient to handle these counterexamples, and thus save the basic idea behind the test. Let us have a brief look at the crucial points of this exchange.

First, consider one of Weiner's examples:

Train Ride: Suppose that Alice and Sarah are in a crowded train; Alice, who is obviously able-bodied, is sprawled across two seats, and Sarah is standing. Sarah says to Alice: 'I'm curious as to whether it would be physically possible for you to make room for someone else to sit down.' The implicature is that Alice should make room. [.. .] Suppose now that Sarah adds: 'Not that you should make room, I'm just curious.' This has the form of an explicit cancellation of the implicature. Nevertheless, the implicature is not cancelled. Sarah is still suggesting, even more rudely, that Alice should make room. [Weiner 2006: 128]

In a case like this, it seems that the sarcastic character of the first utterance will spill over to the attempted cancellation, as it were. ${ }^{7}$ As a result, the attempted cancellation will reinforce the implicature rather than cancelling it. In other words, the cancellation will fail, although it seems obvious that we are dealing with a conversational implicature. ${ }^{8}$

The observation underlying Blome-Tillmann's reply is that even though implicatures of the kind presented in Weiner's example cannot be cancelled in the context in which they are generated, there will always be some other context in which they are not to be understood as

\footnotetext{
${ }^{7}$ Given that it is in fact sarcastic, there is reason to doubt that Sarah's utterance of 'Not that you should make room, I'm just curious.' is really intended as an attempt to cancel the implicature. See Borge [2009] for an interesting discussion of this aspect of Weiner's examples.

${ }^{8}$ The example also seems to show that the admissibility of adding a cancellation clause is not always sufficient for successful cancellation. Although there is nothing infelicitous about Sarah's addition of the cancellation clause, the cancellation seems to fail.
} 
sarcastic, and in which they can be explicitly cancelled in the ordinary way. Consider the following scenario:

Star Trek II: Unbeknownst to Alice, who is sprawling over several seats on the recreation deck, Sarah and one of her engineering officers are testing a portable tractor beam. For the purposes at issue, the tractor beam has to be strong enough to make it impossible for Alice to make room for someone else to sit down next to her. After activating the beam Sarah asks Alice via the intercom:

Sarah: Alice, I'm curious as to whether it would be physically possible for you to make room for someone else to sit down.

Alice: (baffled) Why should I? There's nobody else here who wants to sit down. . .

Sarah: Oh, I'm sorry. I didn't mean to imply that you should make room. We are testing a new tractor beam on you and we are curious as to whether you can do it. This would give us an important indication as to how strong the beam really is. [Blome-Tillmann 2008: 159]

Blome-Tillmann's suggestion is that Grice's notion of explicit cancellability needs to be weakened in order to accommodate counterexamples like Weiner's, and he ends up proposing $\mathrm{EC}^{\prime}$ as a necessary condition on conversational implicatures:

(EC') If an utterance of $P$ conversationally implicates $q$ in $C$, then there is a context $C^{\prime}$ and some form of words $F$ such that utterances of $P$ convey $q$ in $C^{\prime}$ and the assertion of $F$ is admissible in $C^{\prime}$ and cancels the speaker's commitment to $q$ in 


\section{$C^{\prime} .{ }^{9}$ [Blome-Tillmann 2008: 160n]}

So, on the one hand, Blome-Tillmann concedes that there are conversational implicatures that are not explicitly cancellable in Grice's sense (i.e. the sense employed in EC). But on the other hand, he thinks that all conversational implicatures pass the modified test $\mathrm{EC}^{\prime}$, and thus, he concludes that ' $[\mathrm{w}] \mathrm{e}$ do, after all, have a reliable and effective test for conversational implicatures' [Blome-Tillmann 2008: 160].

\section{Cancellation and Felicity}

Blome-Tillmann's modification of EC takes care of the most serious threat posed by Weiner's cases, and in this respect, it is clearly an improvement. ${ }^{10}$ However, it still seems that $\mathrm{EC}^{\prime}$ and the notion of explicit cancellability it employs are not fully adequate. The reason is that $\mathrm{EC}^{\prime}$, just like $\mathrm{EC}$, rests on the assumption that when we are dealing with a conversational implicature, the addition of a cancellation clause is always admissible. ${ }^{11}$ This is a potentially problematic feature of these tests, since there appear to be cases of conversational implicature in which cancellation succeeds even though the addition of a cancellation clause is not admissible in the relevant sense.

Consider sentence (1b) as uttered in reply to (1a), in a context where gender-stereotypical behaviour among children is under discussion: Boys are boys, and girls are girls.

No, boys are not boys, and girls are not girls.

\footnotetext{
${ }^{9}$ Blome-Tillmann initially proposes a stronger principle labelled 'EC*', but in a footnote towards the end of the paper, he points out that the weaker $\mathrm{EC}^{\prime}$ is adequate for his purposes.

${ }^{10}$ It seems less clear that it can handle the worry that there may be cases of failed explicit cancellation where the felicity condition is nevertheless fulfilled (see footnote 8 above). I will not pursue this issue further here.

${ }^{11}$ Indeed, in the passage by Grice quoted at the outset, explicit cancellability is directly characterized in terms of the admissibility of adding cancellation clauses of a certain form.
} 
The literal content of (1a) is trivially true, while the literal content of (1b) is trivially false. Nevertheless, in the circumstances described, an utterance of (1a) will implicate something non-trivial, namely that there is nothing to be done about the behaviour in question, while (1b) will implicate the equally non-trivial content that something can be done about it. This is an instance of what I take to be a quite familiar phenomenon, namely that one can pragmatically convey something substantial by saying something that is literally trivial or even absurd. Now, consider what happens when one attempts to cancel the implicature generated by the utterance of (1b) in a situation like the one just described, by adding a standard cancellation clause like the following:

But of course, there is nothing to be done about their gender-stereotypical behaviour.

It seems that an utterance of (1c) would successfully cancel the implicature generated by the utterance of (1b). ${ }^{12}$ It also seems that if this implicature were to be cancelled in this way, the speaker would come out as conveying the literal content of (1b) - i.e. as literally saying that boys are not boys and girls are not girls - which is manifestly absurd. Thus, successful cancellation of the implicature would seem to render the utterance as a whole $(1 b+1 c)$ infelicitous.

To take a somewhat different, but related example, one can reply to an assertion with a contradiction in order to convey that one finds it highly implausible. Consider the following conversation:

\footnotetext{
${ }^{12}$ Just as an utterance of the corresponding cancellation clause would if the reply to 1a went as follows: 'Yes, boys are boys and girls are girls. But I think you're wrong that nothing can be done about their genderstereotypical behaviour.'
} 
By uttering (2b) in this context, one would seem to implicate that to claim that Stephen King will get the Nobel Prize next year is just as implausible as to claim that $2+2=5$. Now, consider the attempt to cancel this implicature by adding the following: But you're right, Stephen King will probably get the Nobel Prize next year.

Just as in the case with (1b) and (1c), it seems that an utterance of (2c) would successfully cancel the implicature generated by the utterance of (2b). It also seems that if this implicature were to be cancelled in this way, the speaker would come out as conveying the literal content of (2b). In other words, the speaker would seem to express something contradictory. Thus, in this case as well as in the previous one, successful cancellation of the implicature would seem to render the utterance as a whole $(2 b+2 c)$ infelicitous.

The following conversation illustrates another way in which contradictory sentences can be used to pragmatically convey non-contradictory contents:

$$
\text { Are you happy with your new job? }
$$

Yes and no. ${ }^{14}$

An utterance of (3b) in these circumstances would seem to implicate that the speaker is happy with the new job in some, but not all respects. But that implicature can be cancelled by the addition of the following:

\footnotetext{
${ }^{13}$ I owe this example to an anonymous referee.

${ }^{14}$ I owe this example to Eric Johannesson
} 

happy with it in others.

Once the implicature is cancelled, the only thing that remains to be conveyed is an outright contradiction. As in the previous examples, the successful cancellation of the implicature would render the utterance as a whole $(3 b+3 c)$ infelicitous.

The utterances of (1b), (2b) and (3b) (in the circumstances described) are intended to illustrate the more general phenomenon that it is possible to pragmatically convey something coherent by uttering something that is literally incoherent. Insofar as what is pragmatically conveyed can be cancelled with the result that only the literal content remains to be conveyed, any such an utterance can be rendered incoherent by adding a cancellation clause. This is what the additions of $(1 \mathrm{c}),(2 \mathrm{c})$ and $(3 \mathrm{c})$ in the above examples is intended to illustrate. In all of the three cases considered, the result is a successful cancellation by way of an addition of a cancellation clause that renders the utterance as a whole incoherent.

So, cases of the kind exemplified above appear to constitute counterexamples to the assumption that successful cancellation requires that the addition of the cancellation clause be admissible. ${ }^{15}$ The crucial feature of such cases is that the coherence or felicity of the utterance $U$ of the initial clause essentially depends on the conversational implicature that $U$ generates. Thus, when one successfully cancels that implicature, one ends up with an incoherent or infelicitous utterance; in this sense, the addition of the cancellation clause is not

\footnotetext{
${ }^{15}$ Other potential counterexamples include the following: 'Some Dutch men are above average height for Dutch men. In fact, all of them are'; 'Daniel was born, lived a long and happy life, and died, but not in that order'; 'I sometimes lie. In fact, I always do'. These instantiate standard patterns for implicature cancellation, but they also raise some worries. As regards the first two examples, it is not clear that the relevant contents are merely implicated; they also seem to be entailed in some sense (see Davis [1998: 6] for relevant discussion). As regards the third example, one might worry that it is a version of the liar paradox, and as such does not tell us much about conversational implicature and cancellation in general. Although further discussion of these cases and the worries they raise may be of interest, it is not necessary for present purposes. The cases presented in the text are sufficient to prove my point, and I find them more convincing than the ones mentioned in this footnote. Therefore, I will not go into further detail about the latter ones. Thanks to two anonymous referees for very helpful advice on these issues.
} 
admissible. For lack of a better term, let us call such implicatures Felicity-Essential Implicatures, or FEIs for short.

Why is this important? First, given the significance of the notions of conversational implicature and cancellability, we should make sure that we have a proper understanding of them. Second, if we were to accept that successful cancellation requires felicity-call this the felicity requirement on successful cancellation - then it would be tempting to think that one could reliably test for successful cancellation by checking whether the felicity requirement is fulfilled — call this the felicity test for successful cancellation. The upshot of the above discussion is that the felicity requirement does not hold in general, and thus, that the felicity test is not generally reliable. This is important insofar as testing for successful cancellation forms a crucial part of evaluating theories in many different areas of philosophy. ${ }^{16}$

\section{The Risk of Misdiagnosis: A Case Study}

It is worth pointing out that even if there are many cases in which the felicity test gives the right result since there is no FEI involved, we may not always be in a position to ascertain whether or not this holds for the case at hand. In general, we should not expect recognition of FEIs to be an uncontroversial matter. Indeed, whether we are dealing with an FEI, or whether the inadmissibility of the addition of a cancellation clause is due to the fact that we are not dealing with a conversational implicature at all, may itself be a matter of dispute.

For illustration, let us consider an example from the recent debate on indexical reference. Consider an answering machine recording of the following sentence:

I am not here now.

\footnotetext{
${ }^{16}$ Cf. footnote 4 and 5 above.
} 
According to David Kaplan's [1989] semantics for indexicals, (4) is logically false, since it is false relative to any proper context. According to a view that is often associated with Kaplan, ${ }^{17}$ an answering machine occurrence of (4) would express something like the following:

Dthat [the speaker] is not at Dthat [the place of the recording machine] at Dthat [the time of recording]. ${ }^{18}$

On this analysis, an answering machine utterance of (4) would seem to express an absurdity. ${ }^{19}$ However, intuitively it seems that (4) conveys something true and sensible when it occurs as part of an answering machine message. This has led many philosophers to think that Kaplan's theory needs to be (at least partly) revised. ${ }^{20}$

One way to defend the Kaplanian analysis would be to claim that this intuition is to be explained in terms of a conversational implicature. The idea would be that (4) strictly and semantically expresses an absurdity like (5), but that it pragmatically conveys something like the following, via a conversational implicature: Dthat [the time of playback].

\footnotetext{
${ }^{17}$ Whether or not it would be appropriate to ascribe such a view to Kaplan himself may be discussed, but I will not pursue this issue here.

${ }^{18}$ The operator 'Dthat' was introduced by Kaplan [1978; 1989: 521-522], and defined as 'the demonstrative 'that' with the following singular term functioning as its demonstration'. In other words, for any singular term $t$, Dthat $[t]$ is a directly referential term referring to the denotation of $t$. This device is helpful here as it makes clear that the propositions expressed here are singular rather than general.

${ }^{19}$ Of course, the singular proposition in itself is not absurd. But given the way in which (and the circumstances under which) it is presented, it seems clear that it is, and would be taken as absurd by the hearer. (Thanks to an anonymous referee for pointing this out.) Indeed, part of Kaplan's motivation for classifying (4) as logically false was that it could only be true relative to an 'impossible' context (cf. Kaplan [1989: 509]).

${ }^{20}$ For instance, see Predelli [1998a; 1998b; 2011], Romdenh-Romluc [2002; 2006], Cohen [2013], and Michaelson [2014]. A notable exception is Stevens [2009].
} 
This option has recently been considered and rejected by Eliot Michaelson [2014: 536], ${ }^{21}$ by appeal to the fact that an answering machine occurrence of the following sentence seems infelicitous:

I am not here now, but I will be at home at the time when you call (i.e. at the time of playback). ${ }^{22}$

Since the infelicity results from the addition of the cancellation clause, it seems that the addition of this clause is not admissible in the relevant sense. If we were to apply the felicity test for cancellability, we would be in a position to conclude that the attempted cancellation in (7) fails.

However, from the point of view of the proposed Kaplanian view, the conversational implicature in answering machine occurrences of (4) is an FEI. It is essential to the felicity of the answering machine utterance of (4), since if it is cancelled, only the strict semantic content — the absurdity represented in (5)—will remain to be conveyed. So, in this case, one cannot exclude the possibility that we are dealing with an FEI, without thereby begging the question against the Kaplanian view. Therefore, one cannot use the felicity test to show that the attempted cancellation in (7) fails. This illustrates how the felicity test can fail to be applicable in precisely those cases where we would really need an independent criterion for determining whether a putative conversational implicature is successfully cancelled.

As this case study shows, the risk of misdiagnosing philosophically significant cases when relying on the felicity test is not merely an abstract theoretical possibility. Moreover, given that the felicity requirement is mistaken, it should not figure in a proper characterization of cancellability. Of course, there is a price to be paid for giving it up, namely that we will no

\footnotetext{
${ }^{21}$ See also Cohen [2013: 8n] and Cohen and Michaelson [2013: 581-582].

${ }^{22}$ The example is slightly modified to avoid some unnecessary complications.
} 
longer have an independent test for successful explicit cancellation. Instead, we will have to rely directly on our intuitions about whether a given attempted cancellation succeeds. However, this seems like a price worth paying.

\section{Concluding Remarks}

Let me conclude with some brief remarks concerning the consequences of rejecting the felicity requirement for explicit cancellability. First, if we want to stick to something like $\mathrm{EC}^{\prime}$, we need to revise it by deleting the admissibility clause. This would give us the following:

$\left(\mathrm{EC}^{\prime \prime}\right)$ If an utterance of $P$ conversationally implicates $q$ in $C$, then there is a context $C^{\prime}$ and some form of words $F$ such that utterances of $P$ convey $q$ in $C^{\prime}$ and the assertion of $F$ cancels the speaker's commitment to $q$ in $C^{\prime}$.

As pointed out above, dropping the felicity requirement means giving up an independent test for successful explicit cancellation. However, in contrast to Grice's test, application of EC' already relied directly on an understanding of successful cancellation, as well as on the felicity requirement. Thus, strictly speaking, $\mathrm{EC}^{\prime \prime}$ does not differ from $\mathrm{EC}^{\prime}$ when it comes to reliance on intuitions about successful cancellation. In other words, as far as $\mathrm{EC}^{\prime}$ is concerned, dropping the felicity requirement involves no cost at all in this respect.

Second, it may still be fine to appeal to intuitions about felicity in discussing whether or not a given cancellation fails, as long as we are justified in ruling out that we are dealing with an FEI. After all, such intuitions may plausibly be considered as defeasible evidence relevant for determining whether the putative implicature is sufficiently loosely connected to the literal content of the utterance generating it. The problem is just that in doubtful cases like the 
answering-machine example considered above, the felicity test cannot serve as a neutral arbiter, and that limits its usefulness.

Third, it might be thought that one could get around all of this by modifying the notion of admissibility, so that the addition of a cancellation clause counts as inadmissible only if it contradicts the literal content, presuppositions or entailments of the initial clause. One obvious problem with such a notion of admissibility is that it would count the addition of any cancellation clause of the form 'but I do not mean to imply that $p$ ' as admissible. This would be problematic, but perhaps one could avoid this consequence by spelling out the notion more carefully. However, there is another, more fundamental problem, namely that in order to be in a position to employ a felicity test based on such a notion of admissibility, one would first need to identify what is said, presupposed, entailed etc., as opposed to what is merely conversationally implicated. In most cases of interest, this identification will be a matter of dispute. Indeed, that is precisely why it would be so nice to have a simple test that could help us settle the matter. But if the test cannot be employed without first settling the dispute, then it obviously cannot be of any help in settling it. In other words, there would be no significant gain in modifying the notion of admissibility in this way, as this move would render the felicity test useless in precisely those cases in which we would really need it. ${ }^{23}$

Finally, one might insist on the felicity requirement in its original form, and take the existence of FEIs to show that some conversational implicatures are not cancellable. That would be a more radical, and perhaps more interesting claim to make. However, I prefer to

\footnotetext{
${ }^{23}$ This does not mean that we cannot take successful explicit cancellation to require that there is no contradiction between the initial clause and the cancellation clause, as suggested by the characterization of cancellability as retractability without contradiction (cf. Bontly [2012, 294]). It just means that we cannot make use of this condition in settling whether or not a given conveyed content is merely conversationally implicated, in cases where this is not obvious or agreed upon.
} 
confine myself to (what I take to be) the more moderate and plausible conclusion that a successful cancellation need not result in a felicitous utterance. ${ }^{24}$

Stockholm University

\section{REFERENCES}

Blome-Tillmann, M. 2008. Conversational Implicature and the Cancellability Test, Analysis 68/2: 156-60.

Blome-Tillmann, M. 2013. Conversational Implicatures (and How to Spot Them), Philosophy Compass 8/2: 170-185.

Bontly, T. 2012. Modified Occam's Razor: Parsimony, Pragmatics, and the Acquisition of Word Meaning, Mind \& Language 20/3: 288-312.

Borge, S. 2009. Conversational Implicatures and Cancellability, Acta Analytica 24/2: 149154.

Burton-Roberts, N. 1984. Modality and Implicature, Linguistics \& Philosophy 7/2: 181-206.

Cohen, J. 2013. Indexicality and the Puzzle of the Answering Machine, Journal of Philosophy 110/1: 5-32.

Cohen, J. and E. Michaelson. 2013. Indexicality and the Answering Machine Paradox, Philosophy Compass 8/6: 580-592.

Davis, W. 1998. Implicature: Intention, Convention and Principle in the Failure of Gricean Theory, Cambridge: Cambridge University Press.

\footnotetext{
${ }^{24}$ Earlier versions of this material were presented at the Colloquium d'Institut Jean Nicod (Paris), at the final conference of the ESF EuroUnderstanding EUROCORES Programme (Lisbon), and at the Higher Seminar in Theoretical Philosophy (Stockholm). I would like to thank the audiences on these occasions for helpful feedback. Special thanks to Steffen Borge, Jonathan Cohen, Alex Davies, Nat Hansen, Eliot Michaelson, Cathal O'Madagain and Mikael Pettersson for taking the time to read and comment on previous versions of the text (or parts thereof). The research leading to these results has received funding from the European Research Council under the European Community's Seventh Framework Programme (FP7/2007-2013)/ERC (grant agreement no 229 441-CCC), ESF Eurocores Scheme 10-EuroUnderstanding-FP-033 (project CCCOM), and from the Swedish Research Council (Dnr 435-2010-454 and 421-2010-1542).
} 
Dimmock, P. and T. T. Huvenes. 2014. Knowledge, Conservatism, and Pragmatics, Synthese 191/14: 3239-3269.

Finlay, S. 2005. Value and Implicature, Philosophers' Imprint 5/4: 1-20.

Grice, H.P. 1989. Studies in the Way of Words, Cambridge, MA: Harvard University Press.

Kaplan, D. 1978. Dthat, Syntax and Semantics 9: 221-243.

Kaplan, D. 1989. Demonstratives, in Themes from Kaplan, eds. J. Almog, H. Wettstein, and J. Perry, Oxford: Oxford University Press: 481-563.

Michaelson, E. 2014. Shifty Characters, Philosophical Studies 167/3: 519-540.

Predelli, S. 1998a. I am Not Here Now, Analysis 58/2: 107-115.

Predelli, S. 1998b. Utterance, Interpretation and the Logic of Indexicals, Mind and Language 13/3: 400-414.

Predelli, S. 2011. I am Still Not Here Now, Erkenntnis 74/3: 289-303.

Romdenh-Romluc, K. 2002. Now the French are Invading England!, Analysis 62/1: 34-41.

Romdenh-Romluc, K. 2006. 'I', Philosophical Studies 128/2: 257-283.

Stevens, G. 2009. Utterance at a Distance, Philosophical Studies 143/2: 213-221.

Weiner, M. 2006. Are All Conversational Implicatures Cancellable?, Analysis 66/2: 127-130.

Williamson, T. 2000. Knowledge and Its Limits, Oxford: Oxford University Press. 